\title{
Therapeutic Change Processes in Functional Analytic Psychotherapy
}

\section{Procesos de Cambio Terapéutico en la Psicoterapia Analítica Funcional}

\author{
Luis Valero-Aguayo \\ University of Malaga, Spain \\ Robert T. Kohlenberg \\ University of Washington, Seattle, WA, USA
}

\author{
Rafael Ferro-García \\ Clinical Psychological Center CEDI, Granada, Spain \\ Mavis Tsai \\ University of Washington, Seattle, WA, USA
}

\begin{abstract}
This paper discusses the mechanism of change and therapeutic techniques central to Functional Analytic Psychotherapy (FAP). Based on the experimental analysis of behavior, contingencies of reinforcement are viewed as an important mechanism of change leading to significant therapeutic improvements. The issue addressed in this paper concerns how a therapist can make maximum use of contingencies of reinforcement, given that the client's problems occur in daily life. FAP emphasizes the client-therapist relationship as providing opportunities for the immediate shaping and reinforcement of improved behavior. The principles of functional analysis are used to explain how actual instances of daily life problems can occur during the session, providing opportunities for therapeutic change, and then mediating generalization from improvements during the session to daily life. Central concepts discussed in this paper include: clinically relevant behavior (CRB), natural reinforcement, interpersonal processes, the behavioral implications of an intense and emotional therapistclient relationship, private behavior, cognitions as behavior, and the behavioral analysis of language (verbal behavior). Five rules that guide therapists in facilitating intense and transformative work with their clients are also discussed.

Keywords: Functional Analytic Psychotherapy, process change, reasons for change, therapist client-relationship, third wave behavior therapy.
\end{abstract}

Resumen. En este artículo se aborda el mecanismo de cambio y las técnicas terapéuticas que son centrales a la Psicoterapia Analítica Funcional (PAF). El análisis experimental de las conductas ha hecho que se consideren a las contingencias de reforzamiento como un mecanismo importante para el cambio que puede llegar a llevar a mejoras terapéuticas significativas. En este articulo nos centramos en cómo un terapeuta puede maximizar su uso de las contingencias de reforzamiento, dado que los problemas del paciente surgen en su día a día. La PAF hace hincapié en la relación cliente-terapeuta como una oportunidad para moldear y reforzar unas conductas mejoradas. Se emplean los principios del análisis funcional para explicar cómo se pueden dar, durante la sesión, ejemplos reales de los problemas cotidianos del paciente, dándose así oportunidades para lograr el cambio terapéutico y para generalizar estas mejoras desde la sesión hacia el día a día del paciente. Algunos conceptos centrales que se tratan en este artículo son: la conducta clínicamente relevante, el reforzamiento natural, los procesos interpersonales, las implicaciones para la conducta de una relación terapeuta-cliente intensa, la conducta privada, las cogniciones de la conducta, y el análisis conductual del lenguaje (conducta verbal). También se presentan 5 reglas para facilitar un trabajo intenso y transformador de los terapeutas con sus clientes.

Palabras clave: proceso de cambio, motivos del cambio, Psicoterapia Analítica Funcional, relación terapeuta-cliente, terapias de conducta de tercera generación. 
Behavioral treatments based on the principles of operant and respondent conditioning have been shown to be effective in treating a wide range of repertoire deficiencies in children and adults. For example, operant techniques for treating severely disturbed children with language disturbances are well established. Similarly, use of respondent techniques such as exposure is effective in treating adults with anxiety related problems . These early behaviorally-based treatments are sometimes referred to as "first wave" behavior therapy treatment.

Nevertheless, most behaviorally-based psychotherapy delivered in an outpatient setting for more pervasive and general problems such as personality problems, severe depression or existential difficulties are aimed at changing mental states, and usually involve the methods of cognitive therapy. These approaches, collectively known as cognitive behavior therapy, sometimes are referred to as "second wave" behavior therapy.

In recent years, a group of therapies have been devised under the name of third wave behavior therapy. (Hayes, 2004; O’Donohue, 1998; Pérez Álvarez, 2006). These include Dialectical Behavior Therapy by Linehan (1993); Functional Analytic Psychotherapy (Kohlenberg \& Tsai, 1991; Tsai, Kohlenberg, Kanter, Kohlenberg, Follette, \& Callaghan, 2009); Acceptance and Commitment Therapy, ACT (Hayes \& Strosahl, 2004; Hayes, Strosahl \& Wilson, 1999); Integrative Behavioral Couple Therapy (Jacobson \& Christensen,1996); and Behavioral Activation (Martell, Addis, \& Jacobson, 2001; Jacobson, Martell, \& Dimidjian, 2001; Kanter, Busch, \& Rusch, 2009). These therapies are characterized by their ability to tackle psychological problems from a contextual behavioral perspective in which cognitive processes are considered to be just another form of behavior. They share advances in research related to the equivalence relationships between stimuli, rule-governed behavior, functional analysis of language and its repercussion on cognitive and emotional behavior (Fernández Parra \& Ferro, 2006).

Although the third wave behavior therapies share common roots and are theoretically coherent and compatible with each other, they do differ somewhat in their techniques and areas of emphasis. This paper addresses the Functional Analytic Psychotherapy (FAP) view of the process of therapeutic change as well as some of the methods and techniques most closely associated with FAP.

Since FAP is based on the principles of radical behaviorism and behavior analysis (Skinner 1953), the role of contingent reinforcement is emphasized. The effectiveness of contingent reinforcement is among the most well-established empirically supported principles of behavior change. Implementation of contingent reinforcement involves delivering the contingency close in time and place to the behavior of interest.

During the first wave applications of operant conditioning, the patient's behavior (e.g., language disturbances, self-destructive behavior) occurred in the presence of the therapist and in controlled settings such as schools and hospitals (i.e., in-situ). These settings, in turn, enabled direct observation of the problematic behavior that could then be reinforced, shaped, or punished as needed. Similarly, the use of exposure usually was done in-situ; for example, the treatment of a fear of dogs involved exposing the client to real dogs in the natural environment. In these cases, the problem of how treatment was related to the client's daily life was obviated by the fact that the treatment took place in the same environment where the problem occurred (e.g., the hospital ward, the school, or the home of a child). In all these early cases, however, the problematic behavior and its environmental context were directly observed and manipulated during the treatment session. As long as the clinical populations included residents of hospitals, students in classrooms, and young or severely disturbed children, the relationship between the effects of within-session treatment, within-session behavior, and the client's daily life problems was straightforward.

Correspondingly, the application of behavior analytic theory was also straightforward and permeated behavior therapy practice. It was unclear, however, how to apply these behavioral methods to the typical outpatient psychotherapy situation involving a therapist and a client talking to each other, and the client's daily life problems were assumed not to occur in this context. Consistent with this erroneous 
assumption that the client's problems occurred in daily life but not in the therapy session, it also was assumed the therapist could not directly observe and deliver immediate reinforcement for new and improved behavior that would in turn be helpful in daily life. As discussed below, we believe the above assumptions were incorrect.

Based on behavioral principles, FAP asserts that the "functional similarity" that exists between one situation and another has to be taken into account rather than the formal or physical similarities. If problematic behaviors that occur in daily life also occur during therapy, then the therapy environment is functionally the same as those daily life situations (Kohlenberg, Tsai, Parker, Bowling, \& Kanter, 1999). For example, if a client who has a deficient repertoire for making friends or having close relationships has similar problems in relationship to the therapist, the two environments are functionally the same. Similarly, if a client's daily life problems involve uncontrolled expressions of anger, and he or she is also verbally aggressive towards the therapist, then the two environments are functionally equivalent. In these instances, since the problematic behavior occurs during the session, there is a therapeutic opportunity to directly change the behavior as it occurs. Since immediate reinforcement is an especially effective mechanism of change (perhaps the most effective), these are special therapeutic opportunities for producing profound and significant clinical improvements.

Thus, FAP is based on the notion that the client's daily life problems can also occur, in-situ, during the therapy sessions, in the context of the therapistclient relationship, and are subject to the significant changes associated with shaping and contingent reinforcement. Further, it is proposed that the improvements, occurring in-situ, during the therapy session can generalize and transfer to the clients' daily life-also on the basis of functional equivalence. Thus, the methods of FAP are aimed at helping the therapist to develop a therapeutic context that promotes a functional equivalence between therapy and daily life environments such that natural immediate reinforcement and shaping occur (Kohlenberg \& Tsai, 1991,1995a; Kohlenberg, Tsai, \& Kanter, 2009).
Since the therapy environment is essentially the therapeutic relationship, FAP focuses what is happening between the therapist and client in the hereand-now. This means each session is adapted to the individual client. FAP is not about using a group of specific techniques, but rather takes into account the current level of functioning of the client in order to determine if an improvement has occurred and should be reinforced. Furthermore, FAP is a psychotherapy that can either be applied by itself or combined with any other therapies producing synergic results (Kohlenberg, Tsai, Ferro, Valero, Fernández, \& Virues, 2005).

\section{Fundamentals of FAP}

The FAP manuals (Kohlenberg \& Tsai, 1991/2008; Tsai, Kohlenberg, Kanter, Kohlenberg, Follette, \& Callaghan, 2009; Tsai, Kohlenberg, Kanter, \& Waltz, 2009) do not offer a protocol with stages, techniques and procedures, but rather describe how to apply the basic elements of intervention. The key to implementing FAP requires an understanding of what is meant by Clinically Relevant Behavior (CRB) and the application of five therapeutic guidelines or rules. (Kanter, Weeks, Bonow, Landes, Callaghan, \& Follette, 2009; Kohlenberg \& Tsai, 1994a, 1995a, Kohlenberg, Tsai, Ferro, Valero, Fernández Parra, \& Virués, 2005; Tsai, Kohlenberg, Kanter, \& Waltz, 2009; Kohlenberg \& Tsai, 1991, 1994a, 1994b, 1995a; Kohlenberg, Tsai, \& Kanter, 2009).

\section{Clinically Relevant Behavior (CRB)}

There are three types of CRB, and therapists should learn to identify them in order to do FAP. CRB1s are the client's problems that occur during the session. They tend to be under aversive stimulus control and they are frequently avoidance behaviors, including emotional avoidance. For example, consider a client Mr. Adams whose daily life problems include avoiding the expression of positive feelings and receiving these from others. As a result, Mr. Adams has difficulty in establishing and maintain- 
ing close interpersonal relationships. A CRB1 for Mr. Adams would be to engage in the same avoidance with the therapist.

CRB2s are the client's improvements occurring during the session. Thus if Mr. Adams expresses a positive feeling towards the therapist during the session, this is a CRB2. As discussed later, the therapist should be aware of CRB2s (improvements) in order to immediately reinforce them and to achieve maximum therapeutic change.

CRB3s are the clients' interpretations about their own behavior that also include the causes. An ideal CRB3 involves the observation and description of the behavior and the associated reinforcing, discriminating and eliciting stimuli. For example, Mr. Adams's CRB3 might be "I was ridiculed by my parents when I expressed positive feelings toward them, and because of this, I now avoid expressing positive feelings to others. This has interfered with me having close relationships."

\section{The Therapeutic Rules}

Five therapeutic rules for therapists to follow are proposed. They involve identifying, evoking, reinforcing, noticing the impact of reinforcement, and interpreting the client's behavior. Rule 1 (awareness) is to observe or be aware of possible CRBs as they are occurring during the session. In Mr. Adams's case, the therapist would notice that Mr. Adams did not express positive feelings toward the therapist when they were obviously present and it would be appropriate to do so. Rule 2 (often requires therapist courage) suggests that a therapeutic environment should be created that evokes CRB. For example, the therapist could express his own genuine positive feelings or caring for Mr. Adams that in turn sets the scene for Mr. Adams to do the same. Rule 3 focuses on positively reinforcing, in a natural way, the CRB2s. Thus, the therapist would be aware (following Rule 1) of Mr. Adams's attempt to express a positive feeling toward the therapist and would respond in a naturally reinforcing way (e.g., I feel warm toward you when I hear you tell me that you appreciate my efforts in helping you). Rule 4 rule is to observe the reinforcing properties of the therapist's behavior in relation to the client's CRB. In Mr. Adams's case, the therapist ideally would observe an increasing frequency of Mr. Adams expressions of positive feelings and thus could verify whether these CRB2s have been reinforced. Finally, Rule 5 is to describe functional relationships between client behavior and the variables that control it (i.e., the therapist would help Mr. Adams come up with the CRB3 described in the previous paragraph).

\section{The Process of Change}

During the session, the therapist continuously should try to increase awareness of CRBs (Rule 1) and whether these are CRB1s or CRB2s, and he or she is going to shape, encourage (Rule 2), and react in a natural way, to strengthen CRB2s (Rule 3). It is basically a process of continuous shaping. A diagram of important elements of the FAP case conceptualization and the interaction of the five rules in the therapeutic process as shown in Figure 1 (Ferro, Valero, \& López Bermúdez, 2009) can be very helpful in this process.

As shown in the figure, knowing how the client's relevant history plays a vital role in the genesis and continuation of problems can help the therapist (following Rule 5) to derive a behavioral account for current behavior. This account then enters into helping the client explain current behavior in terms of his own history of contingencies (a CRB3). The therapist, in conjunction with the client, then attempts to identify (hypothesize) about how daily life problems might occur in the therapeutic relationship. For example, if a client does not assert herself or question authority in daily life, how might a similar situation arise in therapy (i.e., CRB1). In other words, functional equivalence is established between the problems that arise in the client's daily life and the problems that might arise during the session.

Equivalence is achieved by observing (Rule 1) and evoking these issues [Rule 2 (when in fact it might be in his best interest to be less compliant)]. Similarly, the client's improvements during the session (CRB2s) might entail the client questioning a 
conclusion on the part of the therapist or asking for permission not to do any homework since it will be a particularly busy week (CRB2). The case conceptualization as shown in the figure can help the therapist become aware of when a CRB2 is occurring and then naturally reinforce it (e.g., "Of course you don't have to do the homework if you don't have time."). Given the functional equivalence we could expect the improvement during the session to generalize to daily life.

The likelihood of generalization can be increased by the therapist pointing out the parallels between what is happening in the therapist-client relationship and what happens between the client and others in daily life (Rule 5). These effects are later observed in future interactions (Rule 4), and the client's interpretations and explanations about his behavior (CRB3) are similarly shaped to become more behavioral (i.e., the client refers to problematic situations, notices whether or not he is showing improved or not improved behavior, and identifies whether he was reinforced). CRB3s can also incorporate cogni-

Figura 1.

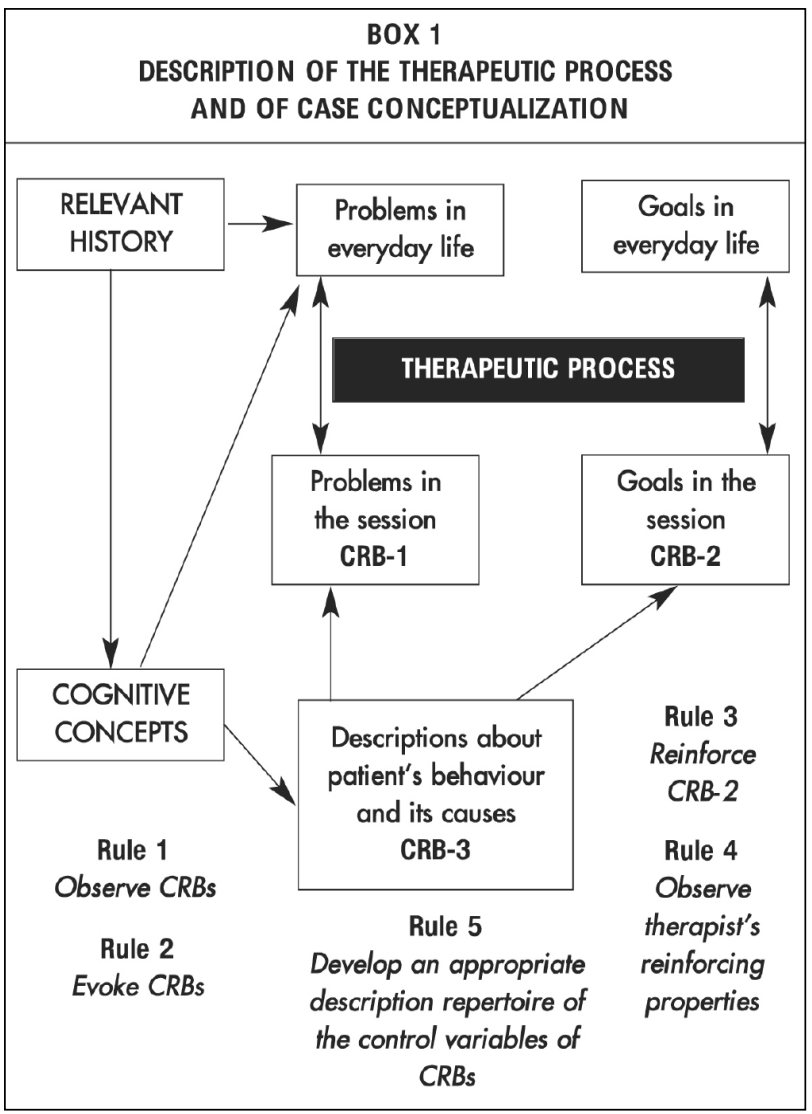

tive concepts or ideas about mental health or psychological wellbeing. The bottom line is that the therapist helps clients generate a descriptive repertoire of the functional relationships that account for their own behavior (Rule 5).

FAP attempts to understand the function of people's problems rather than the form. Rosen \& Davidson (2003) defend the use of empirically proven principles, such as reinforcement and functional analysis rather than using diagnostic categories. In contrast to the psychopathological tradition based on diagnostic categories, behavioral treatment is not directed at eliminating unsuitable behavior or its symptoms but at the sustaining variables. For example, a person who cries every day, says she feels sad, responds badly to other family members, contemplates suicide, has no motivation to work and does not get out of bed, could be diagnosed as having "Major Depression." This diagnosis, however, would not be useful in the treatment because it does not help the therapist identify the variables that have to be changed. One possible cause of the depression is decreased positive reinforcement density in the person's life due to a lack of close interpersonal relationships (Ferster, 1973; Lewinsohn, Hoberman, Teri, \& Hautzinger, 1985); if so, the treatment would focus on using the therapeutic relationship to reinforce interpersonal skills. In another scenario, the depressed behavior could be due to social reinforcement from family members, and the therapist would be especially alert to not do the same during therapy. Thus, FAP orients the therapist towards the relevant variables for change within the psychotherapeutic process (Kohlenberg, Kanter, Bolling, Parker, $\&$ Tsai, 2002).

\section{Aids for Improving Therapist Awareness (Rule 1)}

Callaghan (2006) has devised an approach, Functional Assessment of Skills for Interpersonal Therapists (FASIT), which can help improve therapists' awareness of CRB. The FASIT attempts to evaluate and classify the problems therapists may have during therapy. The manual gives definitions and examples of problem areas within interpersonal exchange. They include; assertion of needs, bi-direc- 
tional communication (providing and receiving feedback), problems with conflict resolution, disclosure skills related to developing interpersonally close relationships, and difficulties with the experience and expression of emotion. This system has proved to be useful in a number of studies (Callaghan, Gregg, Marx, Kohlenberg, \& Gifford, 2004; Kohlenberg, Kanter, Bolling, Parker, \& Tsai, 2002). The FASIT helps to increase expressing support and understanding towards the client as well as establishing a "close relationship", "empathy" and "therapeutic alliance." For this to be achieved, therapists need to have immediate and natural responses that are not rule-governed already established in their repertoire (Callaghan, Naugle, \& Follete, 1996).

\section{Natural Reinforcement}

The use of reinforcement presents one of the biggest psychotherapy dilemmas (Kohlenberg, Tsai, \& Kanter, 2009). As already mentioned, natural reinforcement of desired behavior is the main agent of change within the clinical context. If the therapist tries use reinforcement in a deliberate way, however, effectiveness is compromised because the client might see the reinforcement as manipulative or controlling and engage in counter-control. Natural reinforcement is effective when it is genuine. When applied effectively, the therapist can reinforce the client's behavior and begin to change it. For example, if the client's daily life problem is trusting others but discloses an embarrassing incident to the therapist that he has not revealed to anyone else because of the fear of ridicule or rejection (in other words, the client emits a CRB2), an arbitrary reinforcement (to be avoided by FAP therapists) might be for the therapist to smile and say "Thank you for sharing." This is likely to be arbitrary since it is not what happens in real world trusting relationships. Whereas, if the therapist listens intently and responds in a thoughtful and caring way that shows compassion for what the client is feeling, that likely would be a natural reinforcer that strengthens this CRB2. In following Rule 3, the therapist should naturally reinforce whenever the client shows signs of trust towards the therapist.
Similarly, if the client has problems expressing emotion or sincerity in close relationships, the therapist should first try to structure a therapy environment that invites forming a close relationship with the therapist (Rule 2), notice when the client expresses emotion-a CRB2 (Rule 1), and then express a genuine understanding of the emotional expression and perhaps even reciprocate by being somewhat emotional (Rule 3).

As with all shaping, it should also be highlighted that differential reinforcement is used. Thus, the use of extinction or a mild aversive might play a role to reduce or discourage CRB1s (Schmitt,1985). In general, FAP adheres to the general principles advocated by Skinner in which punishment is discouraged in favor of using positive reinforcement. When punishment is used, however, it is usually best to do so while encouraging a CRB2. So for example, you might say to a client who is having difficulty in forming close relationships, "I just paid you a compliment and you didn't acknowledge it. I really did mean the compliment and I also would have liked it if you would have let me know that you heard me." At some later point when the client does acknowledge a therapist's positive comment, it would be important for the therapist to naturally reinforce this, i.e., "Your acknowledging what I said makes it more likely for me to say positive things to you in the future." (Rule 5)

\section{Functional Analysis of Language in FAP}

The functional analysis of language from Skinner's (1957/1981) perspective is also fundamental in the function and implementation of FAP. It is important for the therapist to understand the functional analysis of language in order to understand the verbal interaction that occurs during the session. FAP uses Skinner's (1957) concepts of "mands" and "tacts" to help the therapist become aware of CRBs (Rule 1).

A tact is a simple description whereas a mand is a request. Given that these terms are functionally described, however, it is sometimes difficult to determine whether clients are manding or tacting based on the form alone of what they say. This 
becomes particularly problematic when a client's statement has the form of a tact but instead is functionally a mand. Consider the example in which a client says "I am feeling suicidal." This may appear to be a tact since it's a description of a feeling, and observation. This statement, however, may actually be a disguised tact that is functionally really a mand asking for caring. That is, the client may be functionally requesting that you pay more attention to him with phone calls outside the session to find out how he is doing, or that you involve family members in watching over him.

This latter case is an example of "hidden meaning” (Tsai, Kohlenberg, Kanter, \& Waltz, 2009; Tsai, Kohlenberg, Kanter, Holman, \& Loudon, in press). One FAP technique is to explore the possibility that what a client says has hidden meaning. In the case of the client saying he is feeling suicidal, the therapist can ask if he is giving an update on his emotional state or whether he is wanting more attention or caring. This understanding is important because it helps the implementation of Rule 1 (watch for CRBs). If the client statement about feeling suicidal is really a request for caring from the therapist or others, it would be a CRB1 since it is a problematic way of obtaining concern or caring from others. The FAP therapist can then suggest, prompt, or shape other more effective ways of gaining caring (e.g., prompting a CRB2 such as "I am feeling lonely and wish someone would pay attention to me."). The therapist can naturally reinforce a CRB2 like this by saying something like "that is a direct request and I will try to help you figure out how to get more attention from others-including exploring ways that I could demonstrate my caring for you." Through the process of shaping, this client's CRB2s can become more sophisticated so that he can engage others skillfully in connection without directly saying "pay attention to me."

The above sequence shows how exploring hidden meaning can help implementation of Rule 1 (the therapist becoming aware of CRB), Rule 2 (evoking a CRB2) and Rule 3 (naturally reinforcing an improvement-a CRB2). Since the interaction is happening in the here-and-now and involves immediate reinforcement, it has the potential of having significant effect on improving how the client relates to signifi- cant others. It should be pointed out that our use of the terms tact and mand is not precisely as Skinner intended but instead is consistent with BarnesHolmes'(2000) interpretation of relational frame theory (Hayes Barnes-Holmes, \& Roche, 2001). For a more detailed analysis of verbal behavior in FAP, see Chapter 3 in Kohlenberg \& Tsai (1991).

\section{Cognitive Therapy and FAP}

It is widely accepted in cognitive behavior therapies that the fundamental causality of thought or emotion is related to an individual's problems, while also recognizing a dual "mental process" that influences behavior. From the point of view of cognitive behavior therapy, it is assumed that by changing the reasoning process and the client's ideas or the emotions associated with thoughts, a change in behavior will occur.

Cognitive behavior therapy is a treatment that enjoys extensive empirical support for a wide range of disorders. Although there are some conceptual differences concerning the role of feelings, memories, and thoughts (Kohlenberg \& Tsai, 1991), FAP can be integrated with and enhance standard cognitive behavior therapy (Kohlenberg et al., 2002). In order to illustrate how FAP can be integrated with and add to cognitive therapy, we focus on one aspect of the rich and rather complex approach originally proposed by Beck and colleagues (Beck, Rush et al. 1979). The cognitive hypothesis states that an antecedent event evokes dysfunctional cognition (e.g., one's believing or assuming) that in turn causes the clinical problem-problematic emotional and behavioral responses. Treatment involves identifying these dysfunctional cognitions and attempting to replace them with more reasonable and accurate cognitions.

A standard CBT therapeutic tool is the assignment of a daily "thought record," a type of diary that includes columns labeled "life situations," "cognitions or beliefs," and" problematic emotional responding and/or behavior." The completed thought record is discussed during the session, and alternative more reasonable and accurate cognitions are then explored. Another CBT method is to urge the client to test the accuracy of the dysfunctional 
assumption by engaging in the avoided behavior during daily life to see if the dysfunctional assumption is supported by reality. For example, consider a depressed client whose daily thought record indicates she does not express dissatisfaction or make requests she assumes (a dysfunctional cognition) terrible things will happen.

A suggested FAP add-on to CBT is to use the existing daily record with the minor addition of another column that asks "does this ever happen during the therapy session in relationship to the therapist?" This add-on will help the therapist become aware of (Rule 1) whether the problematic emotion and dysfunctional belief is happening in the here-and-now in relationship to the therapist (a CRB1). Similarly, if the dysfunctional belief is indeed occurring during the session, the client can be asked to test the accuracy of the assumption by expressing wants and or dissatisfactions to the therapist (a CRB2) to test whether "terrible things will happen."

The net result is that an opportunity is now available for significant improvement due the power of immediate reinforcement for therapeutic change as it actually is occurring (as opposed to exclusively just talking about making these changes during daily life). Thus, rather than just talking about dysfunctional beliefs and ways to alter them, the FAP addon enables this process to be practiced in-situ. Thus, an advantage of focusing on the therapist client interaction during CBT is that dysfunctional beliefs concerning interpersonal relationships can be identified, challenged, and modified in the here-and-now.

Data support the notion that using FAP add-ons to CBT: 1) can be learned and integrated into practice by experienced cognitive therapists, 2) do not compromise the adherence and competence (quality) of the CBT as determined by independent experts, 3) produces improvements in interpersonal functioning, and 4) improves durability of treatment gains (Kohlenberg, et al., 2002).

\section{FAP and Problems of the Self}

FAP uses behavioral principles, and in particular verbal behavior, to account for how the experience of self develops. Most individuals have a stable sense of self, that is, they feel as though there is a part of their experience that is the same across situations and over their lifespan. Such individuals are able to say "I am the same person today that I was at my fifth birthday party even though my thoughts, body, and feelings are quite different." For some individuals, however, the self experience is unstable and includes "losing oneself in close relationships" and the chaotic self experience of individuals diagnosed with borderline personality and dissociative identity disorder.

The FAP hypothesis is that the experience of self closely parallels how a child learns the meaning of the word "I" and associated terms such as "me". The general notion is that "I" is taught by caretakers or parents when they teach such terms as "I want water," and "I am happy." Most parents can correctly prompt these responses when in fact the child "wants water", or is "happy." Since being thirsty or being happy is private (only accessible to the child), the accuracy of what parents teach is dependent on how sensitive they are to the inner state of the child. If parents are highly distracted, insensitive to their children's feelings, or perhaps even mentally ill, they may teach the child to say statements like "I am happy," or "I am thirsty," when in fact they might not be. In this case, the entire meaning of the word "I" may be unstable since it is used in sentences that are not consistent. In such cases the meaning of "I" may not refer to a consistent sense of self and thus can become unreliable and unstable.

The FAP approach to such problems entails that therapists prompt and reinforce an appropriate "I". For example, if a client appears anxious during the session, the therapist may ask her how she is feeling. If she is unable to answer reliably, the therapist might then say "you appear to be anxious, do you feel that way?" Prompting an "I feel anxious" statement when a client is actually anxious provides remedial experience in the use of the word "I" (Kohlenberg \& Tsai; 1991, 1995b; Tsai et al., 2009).

\section{FAP Interpretation of the Literature on Therapeutic Relationships}

FAP emphasizes the client's behavior exhibited during the interaction with the therapist. The thera- 
pist-client relationship becomes the cornerstone for therapeutic change and the functional analysis of this interaction is the key to the entire process. When client problems occur in session, the therapist has the opportunity to shape those behaviors and present contingencies to change them. These interactions should occur in the most natural ways possible in order to facilitate functional generalization with daily life. A critical element in this process is that the therapist is a source of reinforcement, that the therapist "matters" to the client.

The literature on therapeutic processes highlights the importance of the therapist-client relationship, although this concept varies according to the theoretical orientation (e.g., empathy, therapeutic alliance, profound relationships, understanding, transference) (Schaap, Bennun, Schindler, \& Hoogduin, 1993). Along these lines, Orlinsky \& Howard's (1986) article describes how $65 \%$ of the 54 studies they reviewed following Carl Rogers' (1951/1997) therapy had a clear association between the style of therapist-client relationship and the clinical results.

Other research on cognitive-behavioral therapies shows that therapists who are dedicated and very involved in the therapeutic relationship tend to have better clinical results (Gilbert \& Leahy, 2007). An observational study on the different types of therapies, including cognitive-behavioral and psychodynamic, showed that although each orientation had its most frequent techniques (directive and instructional versus dialogue and receptive listening), in all cases the most effective therapies showed a high level of situational verbal responses from the therapist, including affirmation, gestures of understanding and recognition (Stiles, Shapiro, \& Firth-Cozens 1990). Other studies reviewed with meta-analysis show that processes such as "therapeutic alliance" (affectionate, profound, collaborating relationships between the therapist and client) have a smaller correlation, although statistically significant, with therapeutic results (Corbella \& Botella, 2003; Martin, Garske \& Davis, 2000).

An early experiment by Greenspoon (1954) showed the empirical effects of what happens during therapy are the subtle contingencies presented by the therapist. The experiment was later repeated with larger samples by Frank (1971a) \& Leigland (1995). These experiments create a typical clinical session and record certain answers and the contingencies presented by the therapist. In all cases the clients' responses tended to change progressively depending on those contingencies. Frank (1971b) indicated there was a greater influence when the therapist showed signs of authority and prestige. The subtle changes on the part of the therapist were as effective as other more evident changes. Similarly, results suggested that therapists should use affective sentences that have been adapted to the client's language use, and also friendly, emotional language that facilitates client self-reflection.

The FAP interpretation of this literature is that the effect of such variables as "affirmation, gestures of understanding, profound relationships, therapeutic alliance, empathy and receptive listening, friendly emotional language " is to increase the reinforcing properties of the therapist. When therapists are salient reinforcers to their clients, they can affect therapeutic outcome by prompting and reinforcing CRB2s (Kohlenberg \& Tsai, 1991; Tsai, Kohlenberg, Kanter, \& Waltz, 2009).

\section{FAP and the Therapeutic Rationale}

The therapeutic rationale is a statement given to clients at the beginning of therapy that explains how the therapy will be conducted and how it can lead to daily life improvements. It is structured to fit the particular therapist's style and the particular client's problem. For example,

Therapist: You notice I've talked a lot about the two of us, and I want to tell you why. I think that one of the most powerful ways for therapy to be effective is to actually work on your problems as they are occurring. So, for example, if you're upset about your mother or having difficulty relating to your mother, we might sit here and talk about it. That might be helpful. We can figure out how you feel and how she feels and so on and we'll do some of that. But it's more powerful if the problems you're having with her actually come up in your relationship with me. And that did happen. That is, you reacted to me at the end of the 
last session very much in the same way that you've reacted to your Mom.

Client: Right.

Therapist: The therapy is just more powerful and effective if you can actually grasp on these things while they're occurring. So I wanted to let you know why I've been asking you these questions and focusing on our relationship.

The explanation given by the therapist appears to be an important element in the client's experience. In Kanter, Kohlenberg, \& Loftus' (2002) research, the participants received a written explanation in which they related: A) events or stimulus, B) cognitions, and $\mathrm{C}$ ) emotions. One group was given an $\mathrm{ABC}$ explanation, and the other group was given an ACB. The groups then did a task on the computer in which they had to indicate whether they experienced thought or emotion first when shown an image. Results showed that the majority of the participants in both groups, before reading the information, responded according to the cognitive $\mathrm{ABC}$ model. After reading the ACB information, however, members of the ACB group significantly dropped in the cognitive response.

In the second study (Kanter, Kohlenberg, \& Loftus, 2004) the same experimental conditions were used as those mentioned above, but images with different emotional values were employed. After subjects were shown positive, negative, and neutral images, they were immediately asked to mention their automatic thoughts and/or emotions. Both groups were given a written explanation and instructions according to the $\mathrm{ABC}$ or ACB model. The results were similar to the previous test-one group talked about more automatic thoughts while the other group talked more about their emotions. These results suggest that the participants changed their reactions to the images after being instructed to. In other words, the kind of rationale given to clients is going to influence their therapeutic experience and how they approach their work in therapy.

\section{Conclusions}

Given the common origins of the third wave therapies and FAP's commitment to integration with other approaches, FAP shows great promise in terms of integration with Dialectical Behavior Therapy (Waltz, Landes, \& Holman, 2010), Acceptance and Commitment Therapy (Kohlenberg \& Callaghan, 2010) and Behavioral Activation (Busch, Manos, Rusch, Bowe, \& Kanter, 2010).

The FAP approach to outpatient office therapy is based upon behavior analytic principles. FAP also integrates procedures based on recent research in language, which has in turn allowed for a wider range of complex clinical problems to be addressed (e.g., personality, self, and existential problems). What makes FAP unique is the application of contingent shaping and application of natural reinforcement during a therapy session. At the core of FAP is its hypothesized mechanism of change through contingent responding by the therapist to client problems that occur live, in-session. Functional generalization is promoted as the behavior exhibited inside and outside of the clinical session has the same functions; they are sustained in the same way without the therapist having to design a specific program. Cognitive behavior is also incorporated without considering it to be of a mental nature, but rather as behavior that is subject to the same principles as all other behavior. This is all achieved through an intense and emotional therapist-client relationship, where the therapist's abilities to be aware, to be evocative and courageous, and to be naturally reinforcing are the key elements.

\section{References}

Anderson, T., Bein, E., Pinnell, B. J., \& Strupp, H. H. (1999). Linguistic analysis of affective speech in psychotherapy: A case grammar approach. Psychotherapy Research, 9, 88-99.

Barnes-Holmes, D., Barnes-Holmes, Y., \& Cullinan, V. (2000). Relational Frame Theory and Skinner's Verbal Behavior: A possible synthesis. The Behavior Analyst, 23, 69-84.

Beck, A. T., A. J. Rush, et al. (1979). The Cognitive Therapy of Depression. New York: Guilford Press.

Busch, A. M., Manos, R. C., Rusch, L. C., Bowe, W. M., \& Kanter, J. W. (2010). FAP and behavioral 
activation. In J. W. Kanter, M. Tsai, \& R. J. Kohlenberg (Eds.), The practice of functional analytic psychotherapy. (pp. 65-81). New York, NY US: Springer Science + Business Media.

Callaghan, G. M. (2006). The Functional Assessment of Skills for Interpersonal Therapists: The FASIT System. The Behavior Analyst Today, 7, 399-433.

Callaghan, G. M., Gregg, J. A., Marx, B. P., Kohlenberg, B. S., \& Gifford, E. (2004). FACT: The utility of an integration of Functional Analytic Psychotherapy and Acceptance and Commitment Therapy to alleviate human suffering. Psychotherapy: Theory, Research, Practice, Training, 41, 195-207.

Callaghan, G. M., Naugle, A. E., \& Follette, W. C. (1996). Useful construction of the client-therapist relationship. Psychotherapy, 33, 381-390.

Corbella, S. \& Botella, L. (2003). La alianza terapéutica: Historia, investigación y evaluación. Anales de Psicología, 19, 205-221.

Dymond, S. \& Rehfeldt, R.A. (2000). Understanding complex behavior: The transformation of stimulus functions. The Behavior Analyst, 23, 239254.

Fernández Parra, A. \& Ferro García, R. (2006). La Psicoterapia Analítico-Funcional: una aproximación contextual funcional al tratamiento psicológico. Edupsykhé, 5, 203-229.

Ferro García, R., Valero Aguayo, L., \& López Bermúdez, M. A. (2009). La conceptualización de Casos Clínicos desde la Psicoterapia Analítica Funcional. Papeles del Psicólogo, 30, 255-264.

Ferster, C. B. (1973). A functional anlysis of depression. American Psychologist, 28, 857-870.

Frank, J. D. (1971a). Persuasion and healing: A comparative study of psychotherapy. New York: Schocken.

Frank, J. D. (1971b). Therapeutic factors in psychotherapy. American Journal of Psychotherapy, 25, 350-361.

Gilbert, P. \& Leahy, R. L. (2007). The therapeutic relationship in the cognitive-behavioral psychotherapies. New York: Routledge.

Greenspoon, J. (1954). The effect of two nonverbal stimuli on the frequency of members of two verbal response classes. American Psychologist, 9, 384.
Hayes, L. (1987). A contextual approach to therapeutic change. En N.S. Jacobson (Ed.) Psychotherapist in clinical practice: cognitive and behavioral perspectives (pp. 327-387). New York: Guilford.

Hayes, S. C. (2004). Acceptance and commitment therapy, relational frame theory, and third wave of behavioral and cognitive therapies. Behavior Therapy, 35, 639-665.

Hayes, S. C. \& Strosahl, K. D. (2004). A practical guide to Acceptance and Commitment Therapy. New York: Springer.

Hayes, S.C. (1989) Rule-governed behavior: Cognition, contingencies, and instructional control. New York: Plenum Press.

Hayes, S. C., Barnes-Holmes, D., \& Roche, B. (2001). Relational Frame Theory. A postSkinnerian Account of Human Language and Cognition. New York: Kluwer Academic.

Hayes, S. C., Strosahl, K. D., \& Wilson, K. G. (1999). Acceptance and Commitment Therapy. An experimental approach to behaviour change. New York: Guilford Press.

Holzer, M., Mergenthaler, E., Pokorny, D., Kachele, H., \& Luborsky, L. (1996). Vocabulary measures for the evaluation of therapy outcome: Re-studying transcripts from the Penn Psychotherapy Project. Psychotherapy Research, 6, 95-108.

Jacobson, N. J. \& Christensen, A. (1996). Integrative Couple Therapy: Promoting Acceptance and Change. New York: Norton.

Jacobson, N. S., Martell, C. R., \& Dimidjian, S. (2001). Behavioral activation treatment for depression: Returning to contextual roots. Clinical Psychology: Science and Practice, 8, 255-270.

Kanter, J. W, Busch, A. M., \& Rusch, L. C. (2009). Behavioral activation: Distinctive features. London: Routledge Press.

Kanter, J. W., Kohlenberg, R. J., \& Loftus, E. F. (2004). Experimental and psychotherapeutic demand characteristics and the cognitive therapy rationale: An analogue study. Cognitive Therapy and Research, 28, 229-239.

Kanter, J. W., Kohlenberg, R. J., \& Loftus, E. F. (2002). Demand characteristics, treatment rationales, and cognitive therapy for depression. Prevention \& Treatment, 5, Article 41. 
Kanter, J. W., Weeks, C. E., Bonow, J. T., Landes, S. J., Callagahn, G. M., \& Follette, W. C. (2009). Assessment and Case Conceptualization. In Tsai, M., Kohlenberg, R. J., Kanter, J. W., Kohlenberg, B., Follette, W. C., \& Callaghan, G. M. (Eds). A Guide to Functional Analytic Psychotherapy. Awareness, courage, Love, and Behaviorism. (pp. 37-59). New York: Springer.

Keijsers, G. P. J., Chaap, C. P. D. R., \& Hoogduin, C. A. L. (2000). The impact and interpersonal patient and therapist behavior on outcome on cognitive-behavior therapy. A review of empirical studies. Behavior Modification, 24, 264-297.

Kohlenberg, B. S. \& Callaghan, G. M. (2010). FAP and acceptance commitment therapy (ACT): Similarities, divergence, and integration. In J. W. Kanter, M. Tsai, \& R. J. Kohlenberg (Eds.), The practice of functional analytic psychotherapy. (pp. 31-46). New York, NY US: Springer Science + Business Media.

Kohlenberg, R. J., Kanter, J. W., Bolling, M. Y., Parker, C. R., \& Tsai, M. (2002). Enhancing Cognitive Therapy for Depression with Functional Analytic Psychotherapy: Treatment Guidelines and Empirical Findings. Cognitive and Behavioral Practice, 9, 213-229.

Kohlenberg, R. J., Tsai, M., \& Kanter, J. W. (2009). What is Functional Analytic Psychotherapy? En M. Tsai, R. J. Kohlenberg, J. W. Kanter, B. Kohlenberg, W.C. Follette, y G. M. Callaghan, G.M. (Eds). A Guide to Functional Analytic Psychotherapy. Awareness, Courage, Love and Behaviorism. (pp. 1-19). New York: Springer.

Kohlenberg, R. J. \& Tsai, M. (1991/2008). Functional Analytic Psychotherapy. Creating intense and curative therapeutic relationship. New York: Plenum Press. Traducción Servicio de Publicaciones Universidad de Málaga.

Kohlenberg, R. J. \& Tsai, M. (1994b) Functional Analytic Psychotherapy: A Radical Behavioral Approach to Treatment and Integration. Journal of Psychotherapy Integration, 4, 174-201.

Kohlenberg, R. J. \& Tsai, M. (1994a). Improving cognitive therapy for depression with functional analytic psychotherapy: Theory and case study. The Behavior Analyst, 17, 305-319.

Kohlenberg, R. J. \& Tsai, M. (1995a). Functional analytic psychotherapy: a behavioral approach to intensive treatment. En W. O'Donohue y L. Krasner (Eds.), Theories of behavior therapy. Exploring behavior change, (pp. 637-658). Washington: APA.

Kohlenberg, R. J. \& Tsai, M. (1995b). I speak, therefore I am: A behavioral approach to understanding problems of the self. The Behavior Therapist, 18, 113-124.

Kohlenberg, R. J., Tsai, M., Ferro García, R., Valero, L., Fernández Parra, A., \& Virués-Ortega, J. (2005). Psicoterapia analítico-funcional y terapia de aceptación y compromiso: Teoría, aplicaciones y continuidad con el análisis del comportamiento. International Journal of Clinical and Health Psychology, 5, 37-67.

Kohlenberg, R. J., Tsai, M., Parker, C. R., Bolling, M. W., \& Kanter, J. W. (1999). Focusing on the client-therapist interaction: FAP a behavioral approach. European Psychotherapy, 1, 15-25.

Kohlenberg, R. J.; Tsai, M., \& Kohlenberg, B. S. (1996). Functional Analysis in Behavior Therapy. In M. Hersen; R. M. Eisler, \& P. M. Miller (eds.). Progress in Behavior Modification. (pp. 1-24). New York: Brooks/Cole Publishing.

Leigland, S. (1995). An experimental analysis of ongoing verbal behavior: Reinforcement, verbal operants, and superstitious behavior. Analysis of Verbal Behavior, 13, 79-104.

Lewinsohn, P. M., Hoberman, H. M., Teri, L., \& Hautzinger, M. (1985). An Integrative Theory of Depression, in Theoretical Issues in Behavior Therapy (pp. 331- 359): New York: Academic Press, Inc.

Linehan, M. M. (1993). Cognitive-Behavioral Treatment of Borderline Personality Disorder. New York: Guilford Press.

Luciano, M. C. (1999). Application of research on rule-governed behavior (pp.181-204). En J. C. Leslie y D. Blackman (eds.). Experimental and applied analysis of human behavior. Reno, NV: Context Press.

Martell, C. R., Addis, M. E., \& Jacobson, N. S. (2001). Depression in context: Strategies for guided action. New York: W.W. Norton.

Martin, D. J., Garske, J. P., \& Davis, M. C. (2000). Relation of the therapeutic alliance with outcome 
and other variables. A meta-analytic review. Journal of Consulting and Clinical Psychology, 68, 438-450.

O’Donohue, W. (1998). Conditioning and third-generation behavior therapy. In W. O’Donohue (Ed.). Learning and Behavior Therapy (pp. 1-14). Needham Heights: Allyn and Bacon.

Orlinsky, D. E. \& Howard, K. I. (1986). Process and outcome in psychotherapy. In S. L. Garfield \& A. E. Bergin (Eds.), Handbook of psychotherapy and behavior change (pp. 311-381). New York: John Wiley.

Pérez Álvarez, M. (2006). La Terapia de Conducta de tercera generación. EduPsykhé, 5, 159-172.

Rogers, C. R. (1951/1997). Client-centered therapy. Boston: Houghton Mifflin. Traducción Ed. Paidós.

Rosen, G. M. \& Davison, G. M. (2003). Psychology should determine empirically supported principles of change (ESPs) and not credential trademarked therapies. Behavior Modification, 27, 300-312.

Schaap, C. P. D. R., Bennun, I., Schindler, L., \& Hoogduin, K.A.L. (1993). The therapeutic relationship in behavioural psychotherapy. Chichester, UK: Wiley.

Schmitt, J. P. (1985). Client-assumed responsibility: A basis for contingent and noncontingent therapeutic responding. Proffesional Psychology: Research and Practice, 16, 286-295.

Skinner, B. F. (1953/1978). Science and human behavior. New York, Macmillan. Traducción Ed. Trillas.

Skinner, B. F. (1957/1981). Verbal behavior. Acton, MA: Copley Publishing. Traducción Ed. Trillas.

Stiles, W. B., Shapiro, D. A., \& Firth-Cozens, J. A. (19990). Correlations of session evaluations with treatment outcome. British Journal of Psychology, 9, 13-21.

Tsai, M., Kohlenberg, R. J., Kanter, J. W.,
Kohlenberg, B., Follette, W. C., \& Callaghan, G. M. (2009). A Guide to functional Analytic Psychotherapy. Awareness, courage, Love, and Behaviorism. New York: Springer.

Tsai, M., Kohlenberg, R. J., Bolling, M. Y., \& Terry, C. (2009). Values in Therapy and Green FAP. In M. Tsai, R. J. Kohlenberg, J. W. Kanter, B. Kohlenberg, W. C. Follette, \& G. M. Callaghan (Eds). A Guide to functional Analytic Psychotherapy. Awareness, courage, Love, and Behaviorism. (pp. 199-212). New York: Springer.

Tsai, M., Kohlenberg, R. J., Kanter, J. W., Holman, G., \& Loudon, M.D. (in press). Functional Analytic Psychotherapy: Distinctive features. London: Routledge Press.

Tsai, M., Kohlenberg, R. J., Kanter, J. W., \& Waltz, J. (2009). Therapeutic Technique: The Five Rules. In M. Tsai, R. J. Kohlenberg, J. W. Kanter, B. Kohlenberg, W. C. Follette, \& G. M. Callaghan (Eds). A Guide to functional Analytic Psycho-therapy. Awareness, courage, Love, and Beha-viorism. (pp. 61-102). New York: Springer.

Waltz, J., Landes, S. J., \& Holman, G. I. (2010). FAP and dialectical behavior therapy (DBT). In J. W. Kanter, M. Tsai, \& R. J. Kohlenberg (Eds.), The practice of functional analytic psychotherapy. (pp. 47-64). New York, NY US: Springer Science + Business Media.

Wilson, K. G., Hayes, S. C., Gregg, J., \& Zettle, R.D. (2001). Psychopathology and Psychotherapy. In S.C. Hayes, D. Barnes-Holmes, \& B. Roche, (Eds.). Relational Frame Theory. A postSkinnerian Account of Human Language and Cognition. (pp. 211-237). New York: Kluwer Academic.

Wiser, S. \& Goldfried, M.R. (1996). Verbal interventions in significant psychodynamic-interpersonal and cognitive-behavioral therapy sessions. Psychotherapy Research, 6, 309-319.

Artículo recibido: 27/05/2011

Revisión recibida: 11/07/2011

Aceptado: 14/09/2011 